La categoría "ambiente". Una reflexión epistemológica sobre su uso y su estandarización en las ciencias ambientales The category of "environment". An epistemological reflextion about their use and their standardization in Environmental Sciences

\title{
Gerardo Morales-Jasso
}

Instituto Nacional de Antropología e Historia, San Luis Potosí

México

E-mail: gerardosansa@gmail.com 


\title{
Resumen
}

En el presente artículo se analizan tres significados de "ambiente" y se plantean las tensiones epistémicas que implican dos de ellos. La meta es proponer la adopción de uno de los significados para su uso en las ciencias ambientales y con esto disminuir las tensiones epistémicas de su polisemia. Para hacerlo, el artículo distingue "ambiente" de categorías como hábitat, naturaleza, ecosistema. Luego de lo cual, a través de una argumentación epistemológica, se genera una propuesta para las ciencias ambientales en la que ambiente es redefinido en un sentido sistémico. Tal redefinición se propone el cuestionamiento de ideas dualistas que generan tensiones que sólo pueden ser resueltas con base en paradigmas que superen el disyuntivismo mecanicista propio de la epistemología dualista que tienen las ciencias sociales y las ciencias naturales.

Palabras Clave: medio, ambiente, dualismo, complejidad, epistemología.

Recepción: 12-07-2016

Aceptación: $31-10-2016$

\begin{abstract}
The present article analyzes three meanings about "environment" and shows the ephistemic tensions implied by two of them. The goal is to propose the adoption of one of those meanings into the environmental sciences and with this, decrease the epistemic tensions of their polysemy. In order to do so, the article differentiates among "environment" and categories such as habitat, nature and ecosystem. In which, through an epistemological argumentation, it generates a proposal for the environmental science where environment is redefined in a systemic sense. Such redefinition proposes the questioning of dualist ideas that generate tensions that can only be resolved basing on paradigms which exceed the mechanistic disyunctivism proper of the dualistic epistemology that have the social sciences and the natural sciences.
\end{abstract}

Keywords: milieu, environment, dualism, complexity, epistemology. 


\section{Introducción}

Debido a que diferentes concepciones pueden dar lugar a diferentes diseños de investigación, en este artículo se explicitarán las implicaciones epistemológicas de tres distintas concepciones de “ambiente". Para esto se presupone una epistemología sistémica en la que la observación que hacemos del mundo y la forma en que realizamos distinciones de los elementos de la realidad está relacionada con el lenguaje y el aparato conceptual en uso (Lezama 2004, 68).

El caso de /ambiente/ es representativo al respecto, por ser un término impreciso, difuso y que tiene diversas interpretaciones; características que según Erik Swyngedouw, Maria Kaïka y Esteban Castro (2002), facilitan que continúe siendo usado. Tal polisemia genera, demasiado a menudo, que en los diálogos que sobre el ambiente se establecen, académicos con distinta matriz disciplinar $^{1}$ no consigan hablar de lo mismo (Bachelard 1973, 133), lo cual resulta ser un impedimento para el desarrollo de las investigaciones que se centran en el emergente tema de lo ambiental. $^{2}$

El objetivo principal en este artículo será el ambiente, en el sentido de una propuesta que busca deslindar algunos significados atribuidos a este significante en el marco de una matriz disciplinaria compleja. Se presupone que cualquier intento por unir saberes y conocimientos en el sentido del diálogo habría de empezar "con el cuidadoso y tentativo sopesar y comparar los términos usados por estas. Lo que es esencial para cualquier posible entendimiento" (Tellenbach y Kimura 1989, 162). Esto es sumamente pertinente en ciencias ambientales, ya que éstas se practican por académicos formados en distintas disciplinas, con diferentes bagajes, marcos teóricos y metodológicos; incluso con distintas axiologías; lo que ayuda a comprender por qué las ciencias ambientales son "un campo [...] vagamente definido en términos epistemológicos" (Bocco y Urquijo 2013, 93) en el que "desde hace muchos años se necesita la revisión de conceptos que fundamentan las teorías”(Adrián Figueroa 2003, 113).

\footnotetext{
${ }^{1}$ La matriz disciplinar sería uno de los sentidos que Thomas Kuhn dio a paradigma en la primera edición de $L a$ estructura de las Revoluciones Científicas (2006), aunque después limitó los paradigmas a los ejemplares de una matriz disciplinar (Kuhn 1993).

${ }^{2}$ Participan en la dificultad de lograr un diálogo entre las mismas ciencias ambientales que existen distntas aproximaciones, desde las ligadas a las ciencias naturales -ingenierías, ecología- hasta las ligadas a las ciencias sociales y las humanidades -antropología, ética- (Bocco y Urquijo 2013, 84).
} 


\section{Metodología}

Para lograr el objetivo, se recurre a autores de distintas ciencias ambientales, pero la historia ambiental se tomará a modo de ejemplar de las ciencias ambientales (Bocco y Urquijo 2013, 84), aunque recurriendo, en menor medida, también a académicos adscritos a otras ciencias ambientales. $^{3}$

Primeramente, se dará una definición provisional de ambiente a ser comparada con otras categorías similares. Posteriormente, se distinguirán tres significados de ambiente, para al final compararlos con base en la epistemología que los respalda y proponer el de la epistemología convergente con las ciencias ambientales adscritas a una matriz disciplinaria sistémica -más adelante se enuncian algunos autores sistémicos-. Es decir, en este artículo se abducirán varias tensiones del concepto ambiente, luego a través de un axioma (en la historia ambiental debe usarse cierto significado de ambiente), se deducirá la validez de tal axioma en el caso de la historia ambiental para inducir la deducción a un campo más amplio (lo mismo que en historia ambiental, habría de aplicar en las demás ciencias ambientales).

\section{Ambiente como distinto a territorio, hábitat, naturaleza, ecosistema y paisaje.}

El ambiente es definido en la Ley General del Equilibrio Ecológico y Protección al Ambiente (LGEEPA) como "El conjunto de elementos naturales y artificiales o inducidos por el hombre que hacen posible la existencia y desarrollo de los seres humanos y demás organismos vivos que interactúan en un espacio y tiempo determinados." (Ley General del Equilibrio Ecológico y Protección al Ambiente 2014, artículo 2)

A pesar de que esta definición, como veremos más adelante, está mucho más avanzada que otras concepciones de ambiente en uso, en este texto se persigue generar una definición de ambiente aún más operativa desde una matriz disciplinaria sistémica. Primeramente, como "las palabras son centrales para diferenciar concepciones propias del mundo" (Barrera 2011, 122),

\footnotetext{
3 Teniendo en cuenta que quedan distintas discusiones epistemológicas sobre la naturaleza de las ciencias ambientales y que entre las cosas que quedan claras respecto a éstas es que no son ni ciencias sociales, ni ciencias naturales, a inclusión de este artículo en esta revista facilitará su visión por parte de colectivos de pensamiento de tres áreas del conocimiento: ciencias ambientales, ciencias sociales y ciencias naturales. No obstante, se parte de una definición general de ciencia a tomar en cuenta: "Ciencia es el empeño secular ya, de agrupar por medio del pensamiento sistemático los fenómenos perceptibles de este mundo en una asociación lo más amplia posible. Dicho esquemáticamente, es intentar una reconstrucción posterior de la existencia a través del proceso de conceptualización.” (Einstein, 2000, 149, 150)
} 
será necesario deslindar algunos significantes que pueden ser confundidos con el de ambiente, como lo son naturaleza, ecosistema, paisaje, hábitat y territorio.

Naturaleza implica una tensión importante, tal como lo refiere Julio Montané $(1980,17)$, quien indica que la humanidad forma parte de la naturaleza y media entre su ser biológico y la naturaleza que le es exterior a él. Sin embargo, la naturaleza generalmente se concibe como una otredad al considerársele como el medio no humano y no humanizado, lo que implica algo casi inexistente en nuestro mundo (Serrano, Bruzzi y Toscano 2012, 27, 28; Urquijo y Barrera 2009, 234), lo que no significa que la naturaleza como entidad no exista; ya que forman parte de ella procesos como la fotosíntesis, la gravedad, los ciclos de nitrógeno y carbono, así como el ADN (Urquijo y Barrera 2009, 229; Galochet 2009, 9); que aunque sean modificados antrópicamente continúan llevándose a cabo.

La categoría de naturaleza es la más problemática, pues "uno de los esquemas de representación de la realidad con más arraigo en la sociedad contemporánea (al menos en la tradición cultural de Occidente)" es la concepción antropocéntrica que divide al mundo en dos grandes dominios: lo cultural y lo natural. Separación que sirve para fundamentar el individualismo de la lógica capitalista y la idea de que la economía puede funcionar de forma independiente y aislada del funcionamiento de la biosfera (Hernández y Toro 2012, 92). Así que, a través de este esquema, lo natural se opone a lo social, a pesar de que lo social no es sobrenatural. Por lo tanto, desde una epistemología dualista lo natural es lo no antrópico, desde una epistemología sistémica lo social es emergente de lo natural, por lo que tenemos dos significados antitéticos de "natural": natural como antónimo de cultural y natural como el sistema que permite la emergencia de lo cultural (Marín s/f, 53). Las investigaciones sistémicas coinciden con la postura de Bárbara Adam, quen menciona que "Desde una perspectiva temporal, no existe la dualidad naturaleza-cultura" (González y Toledo 2011, 37), que es una distinción arbitraria y difícil de realizar tajantemente, ya que "no puede haber personas fuera de la naturaleza; solo puede haber personas que piensan que están fuera de la naturaleza." (Cronon 1990, 11-14) Incluso las poblaciones ecológicas que formamos los humanos constituyen comunidades al tener interacciones con microorganismos y animales. Desde una epistemología sistémica nosotros mismos como seres culturales, no somos entidades extranaturales, sino que somos emergencias de lo natural; por lo que somos también integrantes de la naturaleza (Vargas 2002). 
Así que, la abstracción de la oposición cultura/naturaleza es operativa al destacar las modificaciones antrópicas, pero pierde operatividad en los casos concretos, los cuales se encuentran en un espectro que va desde lo que carece de interacción con el humano a lo contaminado, pasando por el humano mismo y lo domesticado. Por lo tanto, el concepto "naturaleza" conlleva distintas tensiones difíciles de resolver, las cuales implican una realidad extremadamente compleja y diversa, por lo tanto, significados también diversos que dependerán del marco subjetivo específico que guíe la percepción social (Lezama 2004, 28; Figueroa 2003, 21-45; Pádua 2010, 86). Una forma de disminuir tales tensiones la usan Ely Bergo de Carvalho y Arthur Soffiati, quienes en vez de referirse a la sociedad, se refieren a la "antroposociedad" (Carvalho 2010, 5; Carvalho 2002, 167 y Soffiati 2013a), que aunque parece redundante, implica que la humanidad no es la única que puede atribuirse el ser una sociedad, pues hay otras sociedades además de la humana. Existen también sistemas sociales naturales (enjambres, manadas) y sistemas sociales artificiales (computacionales) tienen vidas sociales (asociaciones) a través de sus poblaciones o comunidades (Maldonado 2009, 151-154; Hobsbawm 1998, 177; Miramontes 1999, 85, 91, 92; Toledo 2016). Así que, al ser la ciencia, a decir de Arturo Rosenblueth, "un modelo de la naturaleza” (Pérez 1998, 209), las ciencias ambientales hacen su modelo al reunir a las dos naturalezas: la naturaleza que se ha nombrado disyuntivamente como tal y la naturaleza antroposocial a la manera de la tercera cultura propuesta por C. P. Snow (1959).

La categoría de ecosistemas se refiere a unidades funcionales que están constituidos por sus componentes bióticos y abióticos y las interacciones y procesos dinámicos que se dan entre ellos, así que implica una división biofísica de la realidad que se basa en el dualismo disyuntivo de la modernidad (Urquijo y Barrera 2009, 231 y Vargas 2002). Sus componentes inorgánicos y orgánicos son relacionados a través de cadenas tróficas en las que se disipa energía: las plantas utilizan la radiación solar para producir sustancias orgánicas a través de la fotosíntesis, la fauna se nutre de ellas y en cada eslabón se pierde entre 80 y $90 \%$ de energía en la forma de calor (Serrano 2012, 28, 29).

La inclusión de la categoría ecosistema permite solucionar la polisemia de lo natural porque requiere de separar la naturaleza antrópica de la naturaleza no antrópica. De modo que se pueda decir que toda antroposociedad produce su propia y selecta perspectiva de la naturaleza, ya se hable de la naturaleza en general (que incluye al humano) o específicamente de la naturaleza 
no antrópica (Lezama 2004, 46). ${ }^{4}$ En tanto que hablar de ecosistema implica hablar de un sentido más restringido de lo natural.

Paisaje es una categoría clave en la geografía (Trinca 2006, 113), pero no es evidente otorgarle una definición satisfactoria, pues implica una sensibilidad que surgió poco después de la caída de la dinastía Han en China, pero que no fue sino hasta doce siglos después que surgió esta sensibilidad en Europa (Berque 1997, 11-18; Urquijo y Barrera 2009, 235, 237-239; Cano 2012, 118, 130). ${ }^{5}$ Humboldt, prefería no descomponer en sus diversos elementos el paisaje "pues el carácter paisajístico dependía en sí de la simultaneidad de ideas y de sentimientos que movían al observador". Pero la modernidad lo fragmentó en paisaje natural y paisaje humanizado "en aras de la particularización y la superespecialización" (Urquijo y Barrera 2009, 239, 241) de la geografía humana y la geografía física. No obstante, el paisaje no puede ser reducido a paisaje natural o paisaje humanizado fruto de esta disociación (Trinca 2006, 117; Cano 2012, 118), ya que que para que la naturaleza se convierta en algo agradable de mirar es porque es mirada como paisaje (Berque 1997, 11-18).

En alemán se vincula el paisaje al Landschaft y en lenguas latinas se remonta a país (Urquijo y Barrera 2009, 233;), que en el francés pays expresa una unidad geográfico-histórica reconocible que contiene relaciones de semejanzas, como la climática y la ecológica; de vecindad, de costumbres, modo de hablar y recuerdos semejantes; está en función de una escala humana que puede ser recorrida a pie, cuyo tamaño es superior al del pueblo -el paisaje abarca lo visible desde un punto de él y por lo tanto, es convergente con la definición de matria de la microhistoria mexicana-, pero es menor que la región (Faucher 2002, 282, 283, 288; Claval, 1998, 15; Urquijo y Barrera 2009, 233).

El paisaje es una unidad física que puede tener diversos significados ya que es una forma de experimentar el espacio que no pretende ser neutra, sino que se sabe que es producto de las relaciones sociales y su relacionarse con la realidad material (Cano 2012, 129, 134; Urquijo y Barrera 2009, 233), por lo tanto, no sólo se refiere a los objetos y seres vivos que contiene, sino a

\footnotetext{
${ }^{4}$ Galochet $(2009,17)$ aborda la historia del uso de ecología en Francia, desde un dualismo que no consideraba al hombre como parte del ecosistema, hasta una aproximación sistémica que no ha tenido tanta aceptación como la dualista. Existe otra historia del concepto en Figueroa 2003, 56-58.

${ }^{5}$ Urquijo y Barrera $(2009,236,237)$ destacan la similaridad del concepto chino para paisaje: shanshui con el altepetl nahua, el yucunduta mixteco, el chuchu tsipi totonaco y en dehe nttoehe otomí; con lo que apuntan a la existencia de la sensibilidad paisajística en tales culturas, además de la china y la europea renacentista. Además, abordan la historia del paisaje en la modernidad (237-247), por lo que tanto Urquijo y Barrera 2009, Cano 2012 y Berque 1997 abordan parte de la historia de la categoría paisaje.
} 
los significados que están en función de la localización del observador; de modo que un mismo ecosistema puede dar origen a distintos paisajes (Trinca 2006, 114-116). Así que el paisaje es una forma de organización del espacio que es cuestión de perspectiva y percepción (Cano 2012, 119, 120, 126), implica contenido espiritual, estético, subjetivo y emocional que le es atribuido al espacio medible (Barrera 2011, 123, 124; Cano 2012, 126. 134), pues se relaciona con una cosmovisión que guía el comportamiento humano (Urquijo y Barrera, 2009, 232). El paisaje se define a través de lo visible, mas no se reduce a lo visible (Trinca 2006, 115); implica también a la memoria y al tiempo pasado, pues está conformado diferencialmente al sufrir del tiempo adiciones, remplazos y eliminaciones de sus componentes conforme pasa el tiempo (Trinca 2006, 115). De allí que "cualquier estudio de paisaje es sólo parcialmente comprensible sin su historia social" (Urquijo y Barrera 2009, 231).

Como se puede ver, aunque el paisaje encarnó una unión de lo social y lo natural en un primer momento, luego la modernidad separó sus componentes, y posteriormente, los geógrafos retornaron al paisaje definido como la unidad espacio-temporal en la cual los elementos de la naturaleza y la cultura convergen en una sólida, pero inestable comunión (Urquijo y Barrera 2009, 230, 231). El paisaje encarna la tensión entre objetivo y subjetivo, ya que es más que mero lugar físico; entre cercano y lejano, ya que se encuentra entre lo observado y la práctica de lo habitado; entre referente y signo, pues es medio físico y también una representación del mismo ya que la manera de mirar organiza el espacio y sus contenidos, con lo que hace emerger al referente para la comprensión del observador- (Cano 2012, 118-124, 128); con lo que el paisaje ha colaborado en diluir la dualidad sociedad-naturaleza a través de una interacción dinámica (Berque 1997, 18-21; Urquijo y Barrera 2009, 240, 241).

Otra categoría que no significa lo mismo que ambiente es hábitat, que en biología se define como el lugar en el que vive un organismo, una población e incluso una comunidad biótica y así se liga con el nicho ecológico, ${ }^{6}$ que implica el lugar del organismo o población en la cadena trófica. Así que el hábitat expresa el espacio físico en el cual una especie vive y se reproduce, el hombre incluso; pero para apropiarse del espacio en el que vive y se reproduce, el hombre incluye una dimensión política que se comprende a través de la categoría territorio, que se

${ }^{6}$ Mientras las especies no humanas tienen nichos ecológicos claros, los seres humanos no; lo que hace que se
diferencie la ecología humana de la de otras especies. Entre otras cosas, no tenemos una función clara en la cadena
trófica, nuestra demografía es socialmente consciente ya que la cultura y la política generan mecanismos de control Nova Scientia ISSN 2007 - 0705, Nº17 Vol. 8 (2), 2016. pp: 579 - 613 
relaciona con el hábitat de la especie en cuestión (Agudelo 2005, 40-42). Territorio es una categoría geográfica cuyo significado expresa el espacio físico en el que una población, sea humana o animal ejerce control o dominio, por lo que el territorio es el lugar donde se producen condiciones materiales y sociales de existencia mediante confrontaciones; por eso es también una categoría política en las que se involucra el poder y por lo tanto, la resistencia. En esta dimensión geográfico-política, un territorio es un espacio que se construye socialmente, el cual es producto de las relaciones de poder. Así que, las territorialidades son construidas y destruidas a través de reordenamientos sociales (Padilla, 2012a, 21, 23, 25-29, 121, 122; Altschuler, 2013, 66-71; Urquijo y Barrera 2009, 231) que no se limitan necesariemante a la extensión de un paisaje o un ecosistema, pues a través de hechos jurídicos el humano establece los límites del territorio que pretende propio y controla el acceso a sus dominios tanto de otros grupos de su misma especie como de otras especies. Ya sea como personas físicas o como personas jurídicas -cámaras de comercio, municipios, estados, departamentos y países- (Agudelo 2005 42, 43), expanden o contraen su jurisdicción territorial a través de apropiaciones y expropiaciones con distinto origen -anexiones, compras, cesiones, ocupasiones militares, etcétera-(Padilla, 2012a, 25-29).

Una vez definidos hábitat, paisaje, territorio, naturaleza y ecosistema, se podrán encontrar varias similitudes entre ambiente y estas categorías descritas brevemente. Sin embargo, no puede ser confundido con estos debido a sus especificidades. Por ejemplo, el ambiente es, como el territorio atravesado por relaciones de poder; y, como se verá paisaje y ambiente tienen varias similitudes, pero a pesar de las mismas, conllevan algunas diferencias que los hacen inconmensurables. ${ }^{7}$

\section{Tres distintos significados bajo un único significante: ambiente}

David Arnold asegura que tal y como lo usamos hoy, el término "ambiente" o "medio", es relativamente reciente (Arnold 2000, 16). ${ }^{8} \mathrm{Al}$ ser "un constructo histórico-social" es un concepto debatido y ambiguo que está "codificado axiológicamente para el cambio", por lo que es una categoría "inevitablemente" sujeta "a interpretaciones diversas" (Aguilar y Torres 2005, 12, 14). En otras palabras, no existe una visión homogénea sobre lo que es el ambiente (Lezama 2004,

demográfico, y por último, la territorialidad humana no está determinada a ciertos ecosistemas y ecotonos, sino que los traspasa (Agudelo 2005, 42).

7 Para una explicación epistemológica del concepto de inconmensurabilidad tanto de Thomas Kuhn como de Paul Feyerabend, véase Dieguéz, (2005, 198-209). 
23). Según el diccionario de la Real Academia de la Lengua Española, "ambiente" proviene del latín ambiens, que hace referencia a lo que rodea o cerca. También tiene la acepción de atmósfera, que implica las condiciones sociales, físicas, económicas de un lugar, es decir, las condiciones externas (Real Academia Española 2014). Como su uso corresponde al alemán Unwelt, al francés milieu y al inglés environment-que se deriva de milieu-, su uso también se refiere a fenómenos físicos y biológicos de la Tierra (Glacken, 1997, xiv; Bocco y Urquijo 2013, 84), por lo que inicialmente, en tanto noción (Agudelo 2005, 40), medio y ambiente implicarían el entorno no humano, es decir, una otredad objetivada que a la vez se volvió producto de la intervención antrópica (Urquijo y Barrera 2009, 234, 239, 242; Galochet 2009, 8).

Pero una vez que se realiza un análisis más profundo surgen tres grandes acepciones de ambiente que se diferencian mediante los subíndices 1, 2 y 3. 1) Una primera acepción, que es la definición más general y común es ambiente ${ }_{1}$, que parcialmente comparte su campo semántico con medio, hábitat, derredor, arena, campo, escenario, contexto, atmósfera, entorno, territorio y locus. Esta se puede definir como el lugar que nos rodea, con sus circunstancias físicas, químicas, biológicas, antroposociales, lo que incluye las culturales y por lo tanto, las económicas y políticas; es una categoría que apunta a la otredad exterior que rodea a lo humano y por lo tanto, expresa la separación moderna entre lo interno y lo externo, entre individuos y su entorno, que se apoya en la disyunción cartesiana entre mente y cuerpo, entre sujeto y objeto. De manera que esta ascepción de ambiente es convergente con el uso popular que tiene el término; es decir, el sentido restringido de ambiente (Aguilar y Torres 2005, 14; Arnold 2000, 11; Toscano y Bruzzi 2012, 479; Lezama 2004, 208; Serrano, Bruzzi y Toscano 2012, 26; Serna y Pons 2005, 181). Al referirse al entorno, ambiente ${ }_{1}$ está en función de lo que no es el sujeto. Por lo tanto, si se usa para referirse a la relación humana con el ambiente se habla de entorno (Lezama 2004, 123 y Rodríguez, 2013, 167), lo que tácitamente significa que no nos consideraríamos parte de éste, por lo tanto, somos exteriores al ambiente. Así que el uso de ambiente ${ }_{1}$ pone el pensamiento en tensión con el dualismo o lo atrapa en él. Lo que también puede suceder incluso en afirmaciones sistémicas como la que sostiene que "la mayoría de las enfermedades son una reacción a un ambiente psíquica o emocionalmente perturbado" (Martínez 1993, 164), en donde el significado se limita a lo circundante.

\footnotetext{
${ }^{8}$ Marc Galochet $(2009,9-26)$ rastrea la emergencia y evolución del environnement en la geografía francesa a los largo del siglo XX, con lo que hace una colaboración a la historia conceptual de éste.
} 
2) Ambiente 2 es naturaleza modificada por la acción humana a través del tiempo (Bocco y Urquijo 2013, 83), una definición que se basa en la distinción aristotélica entre los objetos naturales y los creados por el hombre. Bajo esta perspectiva, el ambiente se distingue de la naturaleza de la misma forma en que se separa la naturaleza artificial que incluye "las transformaciones resultantes de las actividades humanas" de la naturaleza original. Por lo que el ambiente $_{2}$ es naturaleza artificial o "segunda naturaleza" montada sobre la naturaleza original como resultado de las intervenciones de los humanos en la naturaleza. De manera que quienes así lo describen oponen, mediante una transformación antrópica, la naturaleza al ambiente (Aguilar y Torres 2005, 12, 14; O’Gorman 2002, 30, 36, 52; Stewart 1998, 355; Glacken, 2006, 3; Worster 2000b, 45; Merchant 1989, 11; Soffiati 2003b y Castro 2013). Aunque aún se recurre a ésta, es una categoría de transición entre paradigmas o ejemplares epistemológicos vinculados a ambiente $_{1}$ y ambiente $_{3}$. Además, existen otros conceptos que implican esta acepción de coproducción naturaleza no antrópica-antroposociedad que resultan más adecuados como lo son silvosistema e hidrosistema (Galochet 2009, 20-23).

3) El significado de ambiente 3 no puede ser circunscrito o nombrado dentro de los cánones dualistas de la racionalidad moderna, pues es una categoría que nace de una ruptura epistemológica, ya que trata del encuentro de lo humano con lo no humano, por lo que, a decir de Enrique Leff, quien es filósofo ambiental y ecólogo político, no es el medio que circunda a las especies. No es, pues, un factor extracultural (en la práctica, esta concepción niega el significado de ambiente $_{1}$ ), sino una emergencia que se remite a una racionalidad. Ambiente 3 es la articulación no dualista "entre sociedad y naturaleza, entre ciencias sociales y ciencias naturales" (Leff 2006, 27; Leff 2002, 333, 336). Aunque, derivado de las ideas mencionadas anteriormente, habríamos de cambiar la definición anterior por: la articulación no dualista entre antroposociedad y naturaleza no antrópica y por lo tanto, entre las ciencias sociales y las naturales (Aguilar y Torres 2005, 12, 14; Lezama 2004, 14; Worster 1998, 293; Worster 2000a, 13).

Al provenir de una racionalidad compleja que "interrelaciona los procesos ónticos, ontológicos y epistemológicos, lo real y lo simbólico", ambiente 3 , irrumpe como otredad para la racionalización dualista y resignifica las perspectivas sobre lo real. En síntesis, critica y escapa a la epistemología dualista (Leff 2002, 327, 334, 335; Leff 2006, 14, 36; Leff 2005, 16; Bocco y Urquijo 2013, 78, 79). Por eso y por articular síntomas de la disyunción dualista, como son antroposociedad/ naturaleza no antrópica y a las ramas del conocimiento que las estudian por 
separado -ciencias sociales y naturales-, ambiente 3 es una categoría compleja que implica un sistema abierto que articula las aproximaciones naturalistas y sociales de modo que en el ambiente, "el hombre y la naturaleza son indisociables" (Galochet 2009, 8, 9, 13, 15, 18, 24, 25).

Aun si se tomara a un hombre o un conjunto de hombres como "sujeto" y al resto del mundo como lo que le circunda; por su autooganización interior y la disipación de entropía al exterior debido al intercambio de masa, energía e información entre sujeto y entorno; el sujeto habría de ser tratado como sistema abierto, que es auto-eco-organizador por los intercambios e interrelaciones hacia adentro y hacia afuera (Wagensberg, 1998, 49, 149; Foladori 2005, 132; Bertalanffy 1981, 40, 41 y García 2013, 49). En este sentido, ambiente 3 no sería continente, sino que al integrar contenido y continente, enlazaría lo interno y lo externo, la res cogitans y la res extensa, es decir, ambiente ${ }_{3}$ incluye al sujeto, al ambiente ${ }_{1}$ antroposocial y al ambiente $_{1}$ natural no antrópico en interacción y es la consecuencia de epistemología sistémica de la aceptación de la existencia del ambiente 2 .

Ya lo dijo recientemente Guillermo Castro (2015b): "El ambiente es el producto [he de recalcar que producto no es suma] - previsto o imprevisto- de las interacciones entre sistemas naturales y sistemas sociales a lo largo del tiempo." Este cambio de significado de /ambiente/ se liga a una ruptura epistemológica en la que ya no se entiende al ambiente como lo externo al sistema, sino la totalidad resultante de la relación sistema-entorno, y así como los sistemas pueden tratarse como subsistemas de otros sistemas, el ambiente ${ }_{3}$ es un recorte de la realidad que tras su frontera, que es permeable, tiene su propio entorno o afuera (Wagensberg, 1998, 46, 47).

Hacer equivaler al sujeto a un sistema presenta similitudes con el cuerpo grotesco (lejano a la res extensa cartesiana) que rescata Bajtin (1987, 30), en donde el cuerpo es abierto, traspasa sus propios límites y está enredado con su mundo a través de "el coito, el embarazo, el alumbramiento, la agonía, la comida, la bebida y la satisfacción de las necesidades naturales". Sin vínculo con la concepción grotesca y más bien, ligado a la filosofía marxista, la cual reclama la fundamentalidad de que "nuestra unidad de análisis, de percepción, no sea la individualidad de la existencia dual", porque lo sustancial "son las relaciones que se establecen entre las diversas existencias duales"; Juan Carlos Marín (s/f, 34-37, 58) indica que el cuerpo termina "más allá del perímetro de la piel", pues allí "hay un entorno indispensable". Esta afirmación no implica una vuelta a la indiferenciación psicogenética, sino la toma de consciencia de la exageración de la diferenciación entre interior y exterior. Tal como lo que recalca Luis Fernando Macías García 
$(2010,70)$ al recalcar que en los cambios entre observador y la realidad externa a él son tales que las fronteras que los separan son cada vez menos visibles. En este párrafo se ha de notar que las primeras dos, son lecturas complejas de autores que no son propiamente complejos pero que pudieron trascender a su manera el dualismo, mientras que la tercera es ya de un autor influido por la epistemología compleja.

Estas perspectivas se vinculan a las prehensiones, concepto que surge de Alfred North Whitehead, las cuales “absorben de algún modo en su ser lo que está fuera de ellas". Una planta prehende la luz solar. Por su parte, la limadura de hierro prehende o capta el campo magnético en que se encuentra y con esto "convierte ese campo en un modo de su propio comportamiento y responde a él" (Collingwood 2006, 238). El concepto de sistema abierto, que implica "la presencia consustancial del ambiente, es decir, la interdependencia sistema eco-sistema”, permite escapar de la disyunción y de la anulación del sujeto y del objeto. Así que no se puede comprender ningún sistema abierto, más que en su interacción con su entorno, "que le es a la vez íntimo y extraño y es parte de sí mismo siendo, al mismo tiempo, exterior” (Morin, 2007, 45, 69).

Para ambiente, 3 , el sistema se extiende a un segmento del entorno. Puesto que el ambiente está constituido y constituye un acoplamiento de sistemas superiores e inferiores, de modo que a diversas escalas el ambiente es biótico, abiótico y cultural, y ya que todo sistema no sólo es afectado por lo que lo rodea, también lo integra, lo metaboliza y establece diversas relaciones con su entorno: el ambiente es un recorte espaciotemporal de tipo sistémico que no se refiere únicamente a la dimensión espacial externa al sistema, sino que incluye al sistema mismo. De este modo, un individuo es sistema y ambiente a la vez, ya que forma parte del ambiente de otros individuos y de otras entidades, que a su vez forman parte del ambiente del primero. En otras palabras, la humanidad es un subsistema que al crecer fuerza el sistema ambiente que a su vez conforma (Valdivielso, 2008, 303). El ambiente nos rodea a los humanos y los humanos nos rodeamos entre nosotros; nosotros somos ambiente al constituirlo y que nos constituya. Así, ambiente 3 , al integrar antroposociedad y naturaleza no antrópica no plantea a lo ambiental en el afuera de lo social, sino que coloca a lo social como subsistema de lo ambiental. De esta manera, la epistemología compleja da mayor solidez al sentido de ambiente 3 .

En síntesis, ambiente ${ }_{1}$ es una definición dualista al oponer una entidad a su entorno, ambiente $_{2}$ es la definición que se vincula con lo artificial y ambiente 3 es la definición interaccionista. Cada definición de ambiente tiene distintas implicaciones. Para las tres 
definiciones se puede decir que "el cambio ambiental es controlado tanto por factores biofísicos y sociales como por las sinergias entre ellos". Sólo para ambiente 2 y ambiente 3 se puede indicar que el ambiente incluye tanto a lo natural no antrópico como a lo antroposocial, por lo que el ambiente es un "continuum socialnatural o naturalsocial que varía histórica y geográficamente" (Aguilar y Torres 2005, 15, 18), puesto que, tanto en lo urbano como en lo rural, naturaleza y cultura "se hallan tan entremezcladas que sería tonto (e históricamente erróneo) tratar de separarlas" (Arnold 2000, 171). Sólo ambiente 3 trasciende a la definición de ambiente como el telón de fondo del teatro humano e integra al fondo mismo como uno de los actores principales (Hughes 2008, 323). Por esta razón, cuando se afirma que, en la actualidad, "los procesos imperantes son la globalización de los fenómenos sociales y ambientales”, los cuales, además, están interrelacionados (Lugo e Inbar 2002, 18, 19), se está haciendo referencia explícita al ambiente $_{1}$, aunque implícitamente se está construyendo una tensión entre ambiente 1 y ambiente a $_{\text {. }}$ Así pasa también si se sostiene, como algunos marxistas, que "la relación del ser humano con su ambiente es dialéctica", de modo que "no sólo transforma el medio, sino que, al hacerlo, se transforma a sí mismo en sus propias relaciones interespecíficas”, donde se está acudiendo al concepto de ambiente 1 . Pero, a su vez, se genera una tensión que transforma el significado de ambiente $_{1}$ y lo dirige a la categoría de ambiente $_{3}$ (Foladori, 2005, 123).

También existen otras formas de referirse a lo ambiental que son un tanto problemáticas por su abstracción disyuntiva. Una hace abstracciones del ambiente en "ambiente físico" y “ambiente natural” (Merchant 1989, 42; Kahn 2005, 9; Arnold 2000, 11; Glacken 1997, viii, xi, xiv; Arnold 2000, 11; Pádua 2010, 85, 86), los cuales se acostumbran usar intercambiablemente para distinguirlos del ambiente humano o cultural. Así planteados, estos son fracciones del ambiente $_{1}$, pero debido a la inclusión del ambiente humano, ya sea como naturaleza modificada por el hombre o como barrio, vecindario o ciudad resulta que al hablar del ambiente natural para distinguirlo del ambiente humano, se acepta implícitamente la definición ambiente 2 incluso cuandose usa una definición de ambiente. ${ }_{1}$ Empero, esta forma de partir el ambiente no puede implicar al ambiente 3 , pues éste considera que el ambiente físico es la base del ambiente natural no antrópico y del ambiente humano que son particiones de un sistema interrelacionado que abarca seres vivos, agua, suelo, aire y sus relaciones. En otras palabras, la antroposociedad y la naturaleza no antrópica conforman el ambiente 3 , algo que no puede afirmarse del ambiente 1 y no 
totalmente del ambiente 2 . Pero, son precisamente las reflexiones sobre ambos significados y sus

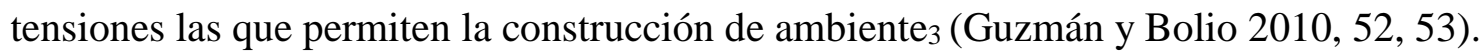

Un ejemplo de estas tensiones se encuentra en el concepto "socioambiental" (Aguilar y Torres 2005, 13; Gallini 2004, 9; Swyngedow, Kaïka y Castro 2002), que tiene sentido al pensar la antroposociedad como factor en la construcción del ambiente, es decir, bajo la definición de ambiente $_{1}, y$, aunque se vuelve redundante bajo la definición de ambiente 2 y pierde totalmente el sentido si se acepta la definición de ambiente 3 , pues en éste se concibe el ambiente como una síntesis de lo natural no antrópico y lo antroposocial, entendido lo antroposocial como incluyente de lo económico y lo político, por lo que lo que la aceptación de la definición de ambiente 3 hace innecesario el concepto de socioambiental.

Actualmente aún algunos científicos ambientales hablan de lo "socioambiental", 9 pero también (especialmente en español) de lo "medioambiental" 10 término ambiguo que se liga al de hábitat natural y por lo tanto, a territorio (Rodríguez 2013, 167, 168). Por ejemplo, Grove habla de environmental history, pero en el capítulo que forma parte del libro Formas de hacer historia, se le traduce por historia medioambiental (Grove 2003, 301-323). Incluso en la "Encuesta internacional: El estado de la historia”, realizada por Carlos Barros de 1999 a 2001, la mayoría de los historiadores encuestados definieron su disciplina como "la ciencia de los hombres y de las mujeres en el tiempo y en el medio ambiente" (Aguilar y Torres 2005, 19), como si medio ambiente fuera el equivalente de espacio. El problema con medio ambiente, es que "medio" es una categoría que puede significar ambiente, mitad, promedio o recurso; tiene cuatro posibles definiciones implícitas: una es redundante -como decir: mas sin embargo- y enfatiza la

${ }^{9}$ Por ejemplo, Guillermo Castro Herrera $(2000,46)$ menciona que "la dimensión socioambiental de la crisis en América Latina resulta tanto de las limitaciones que su inserción en el mercado mundial le impone para dar respuesta a sus problemas sociales, como del ritmo y la escala que esa inserción ha llegado a imponer a la explotación de sus recursos naturales". Otros ejemplos se encuentran en Leff $(2006,9)$ y Micheline Cariño, Lorella Castorena y Antonio Ortega (2013, 24). Otros ejemplos descollantes serían la mesa "Disputas por el espacio en las relaciones socioambientales" del VII Simposio de la Sociedad Latinoamericana y Caribeña de Historia Ambiental (del nombre de la sociedad se podría derivar su rechazo a la primera definición), así como de la página de la tercera edición del evento: http://www.upo.es/simposiohistoriambiental/inicio.htm.

${ }^{10}$ Por ejemplo, Stefania Gallini $(2002,1,2)$ indica que "En muchos casos, el diagnóstico severo tiene fundamento y corresponde a lo que el historiador alemán Joachim Radkau denuncia como el "camuflaje de etiquetado". La presentación (o la mercantilización) de trabajos como investigaciones medioambientales que, sin embargo, no serían tan nuevos si los presentaran bajo otro nombre."

"Pero en los estantes de la producción historiográfica hay también obras que legítimamente se califican como medioambientales, y su crecido número y calidad hace aunque hoy ya no sea cuestionable la existencia de la historia ambiental como campo del saber histórico, tal como lo hacía en 1988 el historiador italiano Alberto Caracciolo, quien, al preguntarse "Qué es la historia ambiental", sentenciaba que o no existía o, si existía, tartamudeaba". Otros 
separación entre humanos y el resto del mundo -como lo hacen Edgardo Datri y Myriam Ortiz, quienes en un texto de epistemología afirman su preocupación por "el impacto de la abrupta expansión de la ciencia y sus aplicaciones sobre la sociedad y el medio ambiente"-(Datri y Ortiz 2004, 243), otra es una definición irónica (pues queda la mitad), otra es inútil a menos que se precise un enfoque estadístico (promedio) y la última (recurso) es utilitarista, pues plantea que el ambiente sirve para un fin (González y Toledo 2011, 25 y Camus 2001, 13, 14). La inutilidad de la redundante y de las otras dos, deja a medio ambiente como una categoría que forma parte de la racionalidad instrumental.

Pero, dejemos provisionalmente de lado otras categorías que comparten campos semánticos con ambiente y analicemos a mayor profundidad los tres sentidos de ambiente mencionados mediante la caracterización de ambiente $_{1}$ como un concepto dualista, la de ambiente $_{2}$ como una categoría histórica de carga dualista y de ambiente ${ }_{3}$ como una categoría sistémica.

El dualismo es disyuntivo y mecanicista por lo tanto, es excluyente, simplificador y unilineal. Tiene su origen moderno en René Descartes, Isaac Newton y Francis Bacon. Por otro lado, el sistemismo se remonta a la cibernética de Norbert Wiener y William Ross Ashby, a Heinz von Foerster, Gregory Bateson y a Ludwig von Bertalanffy. El sistemismo concibe el universo como complejo, no como formado por mecanismos, sino por sistemas formados de sistemas, que a su vez dan lugar a sistemas emergentes, tal como las estructuras disipativas que encuentra Ilya Prigogine (Martínez 1993, 111-115, 151; Wagensberg, 1998, 31-33, 35, 37, 42, 44, 45, 64, 83, 135; Cocho 1999, 45; Hernández 2010, 89, 90).

\section{De la epistemología dualista a la teoría de sistemas. Del significado de ambiente a ambientes}

Antes de ampliar sobre la pertenencia de ambiente $_{1}$ al dualismo y la convergencia de ambiente 3 con el sistemismo, intentaré marcar sus diferencias mediante ejemplos: Tomando en cuenta las enseñanzas semióticas de "La traición de las imágenes" de René Magritte" ${ }^{11}$ considérese las siguientes imágenes. La imagen 1, que puede ser descompuesta en dos conjuntos con cierto grado

ejemplos se encuentran en Camus 2001, 1; Castro 2000, 55; Padilla Calderón 2012b, 100; Cariño, Lorella y Ortega, 2013, 24 y Rodríguez 2013, 167, 168.

${ }^{11}$ En su cuadro "La traición de las imágenes" se muestra el texto "Esto no es una pipa", pero se distingue la figura de una pipa. No mintió el autor, pues aunque pareciera una pipa, no se podía hacer con la pintura lo que se hace con una 
de iconicidad: el individuo (marcado con la letra $a$ ) y su ambiente (marcado con la letra $b$ ). Respondiendo tal representación a ambiente ${ }_{1}$.

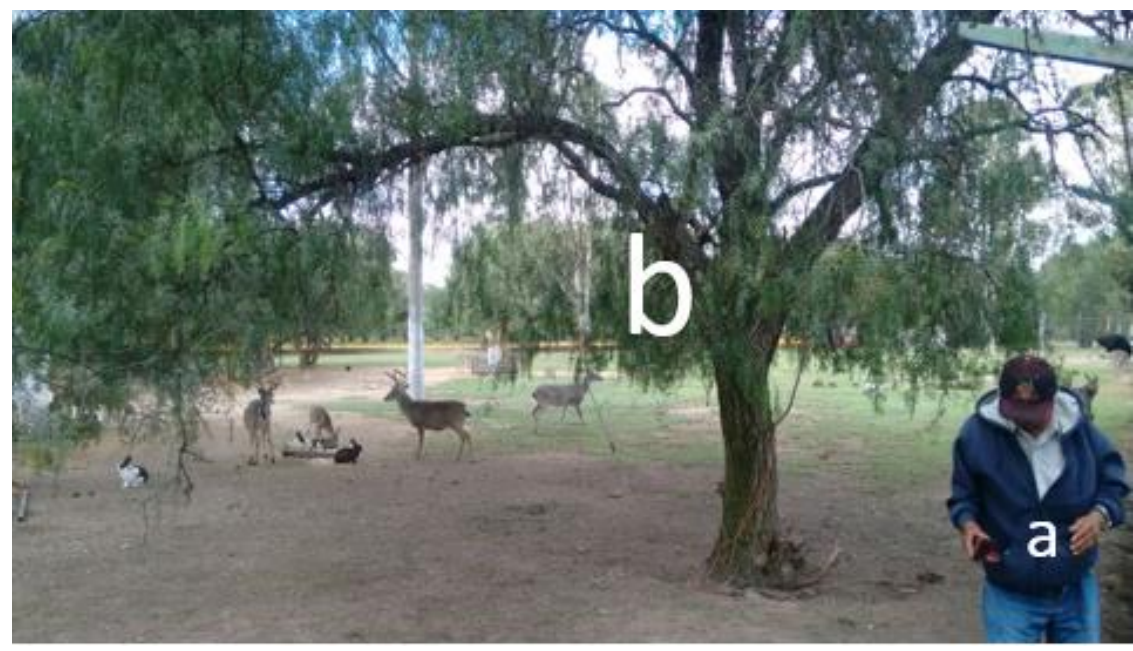

Imagen 1 Fotografía del Lic. Erick Osbaldo Oñate Ramírez

Ahora tómese en cuenta la imagen 2. Lo que vemos es una representación de células (todas las cuales son selectivamente permeables a través de la membrana plasmática) cuyo espacio intersticial está formado por los metabolitos que forman parte de la matriz extracelular (péptidos, hormonas, agua, otras moléculas con su respectiva ionicidad, molaridad y temperatura) que no solo fluye extracelularmente, sino que entra y sale de las células, pues como todo otro sistema, los límites de la célula son dinámicos, lo que hace que sean un tanto vagos y sea difícil decir qué pertenece a la célula y qué no, a pesar de que tal vaguedad es limitada por la clausura operacional de la célula (Pérez 1998, 210; Bertalanffy 1981, 47; Maturana y Varela 1999, 112 $117,140,142,172,173)$.

pipa. La imagen tenía iconicidad para con la pipa, pero por más que la pintura de Magritte o una fotografía de buena calidad evoque una pipa, no puede ser una pipa, puesto que no se puede fumar en ella como en una pipa. 


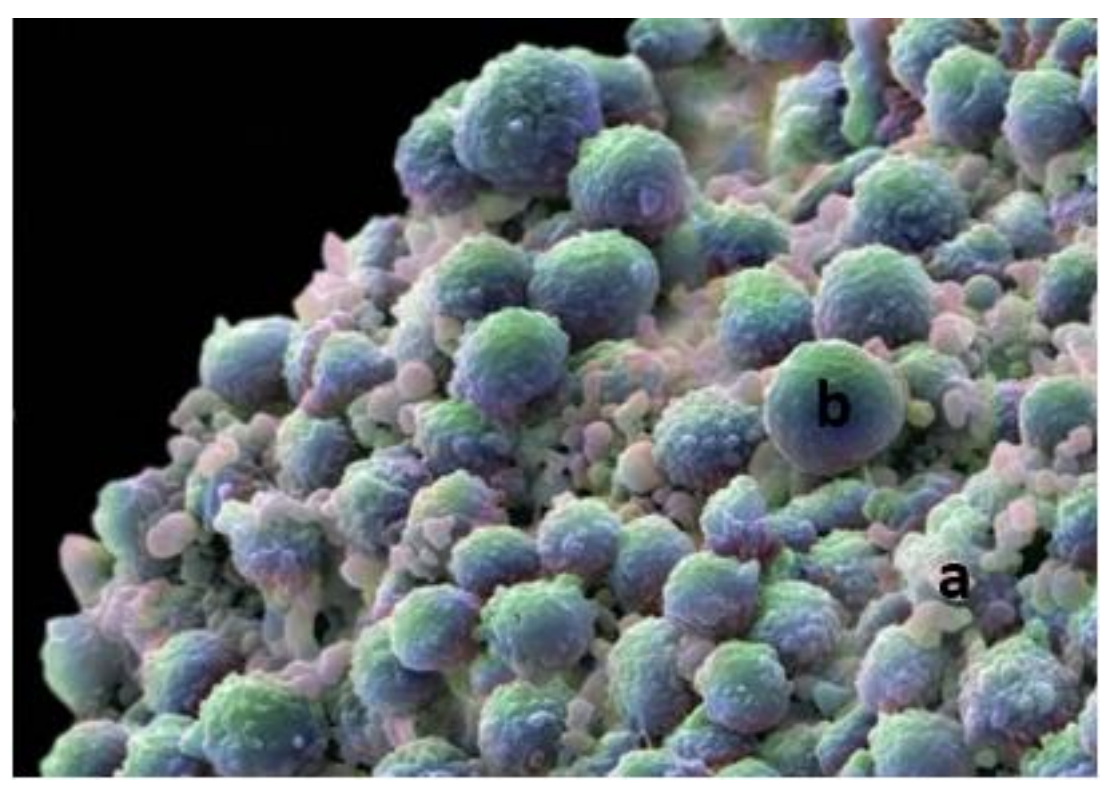

Imagen 1 obtenida de http://kerchak.com/propoleos-abeja-contra-cancer-prostata/ gracias a Jessica Herrera Montelongo

El ícono de la célula marcada con la letra $a$ representa a una célula para la cual la matriz extracelular y las demás células forman su entorno, incluso la célula $b$. De modo que bajo la lectura dada a la imagen 1 podemos decir: "La célula $b$ se encuentra en el ambiente de la célula $a$ ". Sin embargo, para la célula $b$, la célula $a$ es parte de su entorno. En otras palabras, si dejamos de considerar a la célula $a$ como el sujeto del enunciado y consideramos a la célula $b$ como el sujeto del mismo, tendremos que la célula $a$, otrora sujeto del enunciado, se convierte en parte del entorno de la célula $b$ y, por lo tanto, en parte del entorno. Lo mismo aplica para cualquiera de las células de la imagen que no están nombradas. Bajo esta concepción, la relación entidad-entorno es análoga a la de la relación sujeto-predicado que existe del enunciado "Alejandro dio de comer a Chris, Mateo y Ananda" al enunciado "Chris, Mateo y Ananda comieron lo que les llevó Alejandro". Ambas oraciones describen un mismo suceso, aunque su protagonista sea diferente; la inversión no sólo es posible, sino necesaria. A través de estos ejemplos entra en una ligera crisis la concepción rígida de sujeto-entorno caracterizada por la lectura dada a la imagen 1 a través de ambiente 1 .

Por último, obsérvese la imagen número 3: en ésta un grupo de personas se encuentran en un lugar. Si derivamos la interpretación de esta tercera imagen de la interpretación de la imagen 1, entonces tenemos a unos sujetos y su entorno, el cual forma una especie de telón de fondo de los actores humanos. Pero si derivamos su interpretación de la realizada en la imagen 2 , entonces, tenemos que los sujetos, los animales, los árboles, el pasto, el aire, los microbios 
invisibles para la cámara, la reja, las bicicletas, los fotones que permitieron la visión y captura del instante, los insectos que allí estaban, aunque no fueron captados por la lente, la tierra y el oxígeno, así como los demás sujetos allí presentes; cada uno de estos forma parte recíproca del entorno de los demás. Incluso, por ejemplo, los humanos forman parte del entorno del insecto. De igual forma, si la fotografía no hubiera captado al niño con la bici, porque éste no hubiera formado parte del evento fotografiado, entonces, el ambiente de los fotografiados habría mutado. Esta última lectura es una de sistema abierto que relativiza la diferenciación adentro-afuera característica del significado dualista de ambiente, al plantear como intercambiables a sujeto y entorno por considerar la distinción como un mero formalismo.

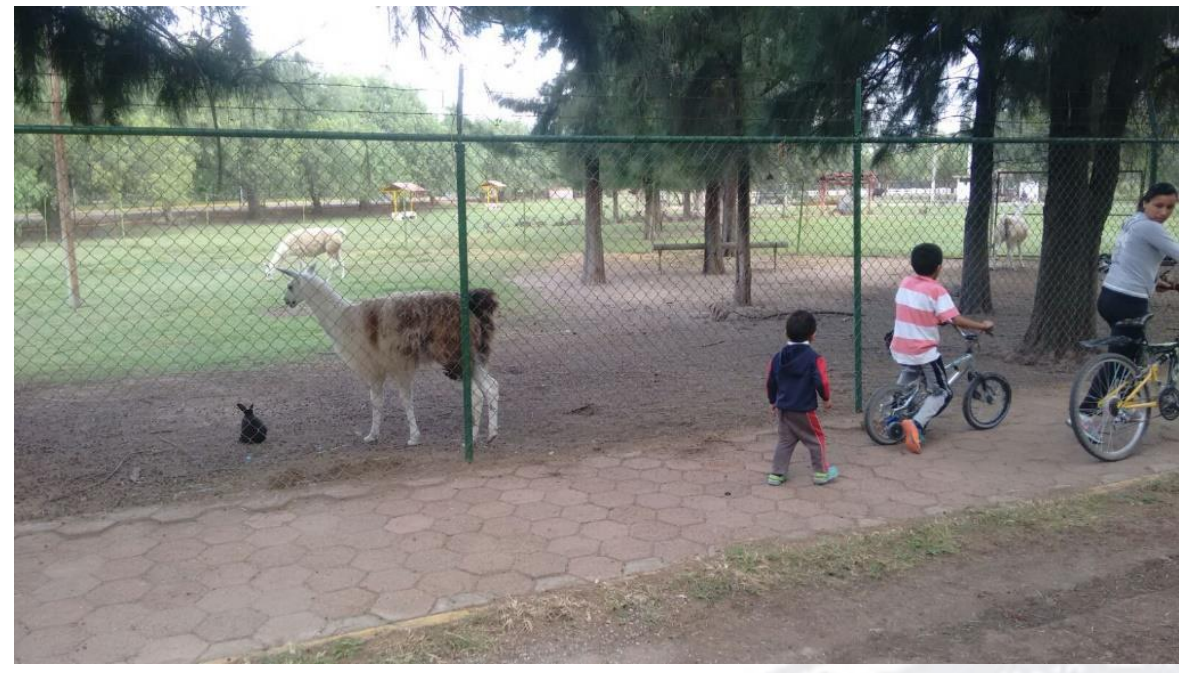

Imagen 3 Fotografía de Erick Osbaldo Oñate Ramírez

Si bien la lectura dada en la imagen 1 es convencional y ambiente se vuelve un término controvertido y problemático en la lectura de las imágenes 2 y $3,{ }^{12}$ estas últimas dos lecturas revelan la arbitraria demarcación entre sujeto y entorno, y a su vez, permite la entrada de ambiente $_{3}$ que abarca, tanto lo natural como lo social, en toda la intercambiabilidad que tienen según el enunciado que estemos formando. Tal significación de ambiente implicaría que un sistema $a$ actúa como parte del ambiente de un sistema $b$, el cual a su vez forma parte del ambiente del sistema $a$. Esto es convergente con la definición de von Foerster de ambiente como la representación de las relaciones entre objetos y eventos, siendo que objetos y eventos no son experiencias primitivas, sino que son representaciones de relaciones (Foerster 1991, 69).

\footnotetext{
${ }^{12}$ La interpretación plasmada de la imagen 2 y el enunciado reiterado, son lecturas que permiten la transición de ambiente $_{1}$ a una mejor comprensión de ambiente ${ }_{3}$. Nóese que no es correspondiente a ambiente 2 , sino a ambiente 3 .
} 
¿Pierde validez el significado de /ambiente/ al cambiar desde un origen dualista hasta un significado sistémico? Según Bachelard, "El lenguaje de la ciencia está en un estado de revolución semántica permanente." Así que ni los significados ni los datos científicos han sido inequívocamente estables: El péndulo ya no se considera una piedra que cae, como en tiempos de Aristóteles. El oxígeno ya no se piensa como aire desflogistado. En el electromagnetismo hubo una ruptura con el sentido común del uso de la palabra "condensador", ya que un condensador eléctrico no condensa la electricidad. Cuando una palabra del antiguo código científico se entrecomilla implica un cambio de significado que afecta la construcción de la experiencia (Bachelard 1973, 52, 229, 230, 231). De allí que "evaporación”, "gota", "temperatura" sean términos que por su redefinición son inconmensurables entre la física clásica y la física nuclear, de modo que su significado en una matriz disciplinaria no tiene sentido en la otra (Kuhn 2006, 227; Bourdieu 2003, 46). ${ }^{13}$ Por otro lado, con las colaboraciones de Einstein a la teoría de la relatividad se tuvo que pasar de un significado de espacio funcional a la física newtoniana "como algo que existe objetivamente, con independencia de las cosas", necesariamente plano, isotrópico y con presencia de materia que para Einstein es propio "del pensamiento precientífico", a un sentido relativo de espacio en el que existen "un número infinito de espacios en mutuo movimiento" (Einstein 2000, 95; Kuhn 2006, 266; Feyerabend 1989, 123, 124).

Al igual que /ambiente/ cada uno de estos significantes ya existía, pero se usaron para expresar nuevas realidades ligadas a realidades y signos conocidos (aún si se hubiera recurrido a un neologismo, habría que explicarlo recurriendo a los códigos conocidos). Como no existe un lenguaje absoluto, neutral y objetivo al que aspirar, esta experiencia semiótica en la que el lenguaje científico toma distancia del lenguaje ordinario, y/o del de una matriz disciplinaria previa, es una necesidad de las revoluciones científicas que conlleva tensiones e inercias. Por lo mismo, es uno de los primeros impedimentos para introducir nuevas ideas en un marco teórico convencional con sus respectivos significantes y significados convencionales (Martínez 1993, 103, 104, 126; Kuhn 2006, 235, 261, 291, 294).

El científico ambiental se enfrenta a este problema semiótico y a la vez epistemológico precisamente por las categorías que requiere usar para estudiar la realidad ambiental. Lo que es

\footnotetext{
${ }^{13}$ Paisaje, una categoría abordada aquí, también ha sido una categoría cuyo significado ha mutado a través de los siglos (Urquijo y Barrera 2009, 233, 234), "y, por lo tanto, su uso como herramienta analítica debería cambiar [...], los conceptos 'envejecen' y hay que remplazarlos y de mantenerlos, como es el caso que nos ocupa, debemos estar
} 
razón suficiente como para examinar las categorías que usa y someterlos a la crítica, especialmente, “cuando funcionan delicadamente, sutilmente.” (Bachelard 1973, 110; Wallerstein 2004, 64)

Con las ciencias ambientales, surgió la necesidad de aceptar un nuevo sistema de categorías sobre los fenómenos, por lo que habría que coincidir con el nominalista anticuado en que "nuestros sistemas de clasificación son productos de la mente humana", pero también con el nominalismo trascendental kuhniano en que estos sistemas de clasificación pueden "alterarse radicalmente" por la interacción en el mundo. Thomas S. Kuhn ha mostrado que

Las categorías han sido alteradas y pueden ser alteradas de nuevo. Difícilmente podremos evitar aproximarnos a la naturaleza con nuestras categorías, problemas, sistemas de análisis, métodos de tecnología y de aprendizaje presentes.

Así que habría que tener en cuenta que partimos de un realismo ingenuo cuando pensamos como si de hecho estuviéramos usando clases naturales, verdaderos principios de ordenación. No obstante, en el curso de la reflexión histórica nos percatamos de que las investigaciones más preciadas pueden llegar a ser reemplazadas. [...] En resumen, la idea es la siguiente: investigamos la naturaleza como si estuviera ordenada en las clases naturales que emiten nuestras ciencias actuales, pero al mismo tiempo sostenemos que estos mismos esquemas constituyen sólo un suceso histórico. Es más, no hay un concepto de la representación correcta y última del mundo (Hacking 1996, 133, 134).

Basada en nuevos presupuestos epistemológicos, la estructura conceptual de la teoría científica también se enfrenta al cambio. Aunque esto implica la eliminación de algunos conceptos y sus usos, así como la introducción de nuevos conceptos, "en su mayor parte, los viejos conceptos son conservados en forma modificada y las viejas observaciones son conservadas con nuevos significados" (Brown 1998, 181). Por lo tanto, la categoría ambiente 3 sólo supera algunas críticas hechas a categorías anteriores. Rebaraja y recombina las ideas que ya tenemos dando lugar a una noción no totalmente nueva ex nihilo, sino que es la modificación de las nociones asociadas a ambiente y $_{1}$ ambiente $_{2}$ a través de una epistemología diferente a la que respalda el uso de tales significados, que se vinculan a conceptos anteriores, pero que se conservan todavía en nuestra trama conceptual. Al tener ambiente, un significado distinto con

conscientes que su contenido ya no es el mismo del momento de su creación y que se debe cambiar." (Trinca 2006, 117) 
ambiente 3 , genera nuevas experiencias (la experiencia nueva replantea la experiencia antigua; $\sin$ esto, no existe experiencia nueva).

Aunque ambiente ${ }_{1}$ ayudó a formar a ambiente $_{3}$, su uso dentro de una disciplina que se está desprendiendo de sus influencias dualistas es perjudicial (Bateson 2006, 200; Bachelard 1973, 145) al no fomentar la comprensión de lo ambiental en toda su complejidad. La distinción entre interno y externo continúa en la complejidad, pero es modificada, ya que "no está claro qué sea lo exterior y qué lo interior, puesto que eso que llamamos realidad sólo se puede captar a partir de unas categorías y dispositivos interiorizados” (Serna y Pons 2005, 181). Así que, ¿es válido hacer referencia al "hombre y su ambiente", o afirmar que los problemas ambientales no pueden ser analizados "en relación con los procesos económicos, demográficos, urbanos y sociopolíticos"? (Lezama 2001, 208) Si bien estas concepciones pueden ser fácilmente identificadas con ambiente $_{1}$ y ambiente $_{2}$; al concebir la antroposociedad como un subsistema de lo ambiental, sólo tiene sentido indicar que la antroposociedad puede producir daños al ambiente en el sentido en que la enfermedad de un órgano del cuerpo afecta al cuerpo en su conjunto (Serrano, Bruzzi y Toscano 2012, 21, 22; Castro 2015b). Sólo en ese sentido puede leerse desde ambiente $_{3}$, y no desde ambiente 1 que, si deseamos un ambiente distinto, tendremos que crear una antroposociedad diferente (Castro 2015a). Dicho planteamiento es afín a la propuesta sistémica de eliminar el dualismo sujeto/objeto e implica elaborar investigaciones en las que el académico renuncie a considerarse fuera del sistema investigado y que al integrarse a él como un subsistema más, acepte que co-construye el sistema del que también es partícipe (Ortiz, Duval, Andrade, Espinoza y Madrigal 2011, 138, 139; Pakman 1991, 26).

En resumen, la categoría de "ambiente", planteada como ambiente 3 expande la visión de la ciencia no desde una epistemología dualista, donde sería contradictoria, sino afín a la complejidad. Esta categoría supone un distanciamiento respecto de los códigos ordinarios, (lo que equívocamente se conoce como lenguaje ordinario), que en este caso está ligada a los paradigmas dualistas. Por esta razón, y con el fin de evitar confusiones, para las perspectivas complejas surge la alternativa de dejar de usar ambiente ${ }_{1}$ y sustituirlo por entorno, así como dejar de usar ambiente $_{2}$ y sustituirlo por naturaleza antropizada. Es decir, el significante /ambiente/ no mutó con la complejidad, pero sí cambió su significado y su referente, lo que supone tensiones epistemológicas cuando en las ciencias ambientales es usado ambiente ${ }_{1}$, que es la concepción dualista de ambiente. 


\section{Conclusiones}

Si el científico ambiental usa sin crítica alguna la categoría ambiente, puede llegar a validar implícitamente el dualismo como forma de conocer el ambiente y continuar la oposición humanidad/naturaleza no antrópica, pero si lo critica encontrará que el uso de ambiente ${ }_{1}$ en una afirmación como las de las ciencias ambientales genera una tensión epistemológica que sólo se puede resolver con la carga teórica que está vinculada a ambiente 3 . La cual implica que los científicos ambientales hayan realizado una síntesis de las ramas dualistas del árbol del conocimiento: las ciencias naturales, las ciencias sociales y las humanidades de modo que tengan en cuenta lo natural no antrópico tanto como lo antrposocial. Pero de hacerse así, sería una contradicción entender ambiente como ambiente ${ }_{1}$. Si utilizan socioambiente, también sería contradictorio llamarse científico ambiental, ya que en todo caso quienes usan este concepto coherentemente podrían autonombrarse científicos socioambientales y reproducir el significado de ambiente $_{1}$ y a la vez abogar por la inclusión de lo antroposocial. En síntesis, dentro de la complejidad, algunas convenciones semióticas utilizadas en ciertas enunciaciones no necesariamente serían válidas, pues todo indica que utilizar "medioambiente", "socioambiente", "ambiente 2 ", "ambiente 1 ", así como "ambiente físico" y "ambiente natural” estaría contraindicado por el dualismo que implica su uso y la falta de coherencia epistémica que causaría. Por lo que el uso correcto de ambiente dentro de las ciencias ambientales sería el de ambiente $_{3}$, que es una versión nueva de una vieja categoría, posicionada en una matriz disciplinaria compleja (Brown 1998, 158). Sin embargo, ¿qué pasa si se busca hacer referencia al ambiente $_{1}$ ? En ese caso, se podría sustituir por entorno para evitar la polisemia de ambiente. Obviamente, esta pequeña innovación resulta tan destructiva como constructiva, pues exige el rechazo del dualismo que permea aún entre los estudios de ciencias naturales y de ciencias sociales (Kuhn 1993, 232).

Esto significa que, como las ciencias ambientales implican una superación del dualismo y una epistemología sistémica que va más allá de un simple énfasis ambiental (Bocco y Urquijo 2013, 76), pues implica el cambio teórico profundo de una propuesta de síntesis: un cambio epistemológico. A través del cual, el investigador deberá cuestionar si existen otros conceptos y categorías que se arraigan en el dualismo. Será útil que el investigador se pregunte si hace referencia a otros significados epistemológicamente inconsistentes con el significado que le da a ambiente. Pero, aunque el investigador requerirá hacerse esta pregunta una y otra vez, no podrá 
responderla a menos que sea consciente de la epistemología que utiliza. Una vez que lo ha hecho, deberá ubicar las categorías que no corresponden a su epistemología, de modo que para no oscurecer lo que desea significar, los ha de abandonar y sustituir por otros; con lo que ha de “efectuar ajustes sucesivos de vocabulario" (Galochet 2009, 16). ${ }^{14}$ Esto implica el abandono de metáforas mecanicistas y la revisión de categorías que están en uso como "mecanismo", que implica unilinealidad y determinismo (Foladori, 2005, 129); "sobredeterminación”, que es usado por el marxismo a pesar del rechazo de influencias mecanicistas (Foladori, 2005, 118, 127, 131, 132); "capital cultural" y "capital social" como metáforas economicistas que quedan como remanentes del dualismo en la sociología de Pierre Bourdieu, quien intentó romper dualismos con categorías como "habitus” y “campo" (Rojas y Pérez-Rincón 2013, 47; Collado 2005, 36); así como el concepto "recurso" (Autor 2016) que es una de las expresiones dualistas más refinadas e interiorizadas de las culturas occidentales modernas (Cariño 2003, 40) y a la vez uno de los conceptos en los que se han apoyado las ciencias ambientales, las cuales critican el instrumentalismo, el dualismo, el disyuntivismo, el mecanicismo y todas las bases teóricoepistemológicas del concepto recurso natural.

Así que, habiendo sugerido inductivamente desde la historia ambiental que las ciencias ambientales podrían cambiar el significado que dan a ambiente para asumir el de ambiente ${ }_{3}$ quedaría por corroborar esta teoría deductivamente por posteriores investigaciones realizadas desde cualquiera de las ciencias ambientales. También quedaría preguntarnos ¿incluyen las demás ciencias ambientales a lo natural no antrópico y lo antroposocial y a su vez se definen desde ambiente ${ }_{1}$ ? O bien, ¿incluyen las demás ciencias ambientales las relaciones mutuas entre antroposociedad y naturaleza no antrópica pero se definen desde ambiente 3 ? Responder estas preguntas y las consecuencias observacionales de las tensiones que generen en las demás ciencias ambientales nos permitirá realizar una transición de la polisemia de ambiente reinante a ambiente $_{3}$, lo que implicará un cambio de matriz disciplinaria y de sus correspondientes

\footnotetext{
${ }^{14}$ Paul K. Feyerabend (1989) muestra que esto no es algo que esté fuera de lo común en la ciencia. Para llegar a la teoría newtoniana fue necesario dejar atrás concepciones aristotélicas. A su vez, para poder generar la teoría de la relatividad general, fue necesario cambiar los significados de espacio, tiempo y masa, cuyos significados newtonianos mantenían la física atrapada en un esquema preeinsteniano. Por lo que la práctica científica no comprueba las reglas empiristas que plantean que la reducción y la explicación deben darse por deducción y que los significados de los términos (observacionales) son invariables tanto respecto a la reducción como a la explicación. Por lo tanto, el caso propuesto en el presente artículo tiene mucho en común con los que plantea Feyerabend para la física en Límites de la ciencia, ya que las diferencias se explican también por inconmensurabilidad.
} 
paradigmas, que a su vez permitirán eficientar el diálogo entre los diversos profesionales de lo ambiental.

No obstante, los cambios aquí señalados no pueden ser sólo realizados como consecuencia inmediata de la solución de tensiones aquí propuesta, es decir, no basta la lógica y la reflexividad (Autor y Herrera 2015-2016, 89, 90) para generar un cambio de matriz disciplinaria en los colectivos de pensamiento; lo cual es algo que ya enseñaron tanto el físico Thomas Kuhn como el matemático Imre Lakatos (Klimovsky 1997, 355-380), incluso, antes que ellos, el médico Ludwig Fleck (1986). El cambio aquí esbozado, si acaso sucediera, tiene que ver también con el horizonte de expectativas de los colectivos de pensamiento que abordan lo ambiental, ya sea desde las ciencias sociales, desde las ciencias naturales o propiamente desde las ciencias ambientales. El diagnóstico epistemológico aquí establecido, así como la alternativa propuesta que podría solucionar las tensiones encontradas, son solo una alternativa. En la práctica, será el colectivo mismo de las ciencias ambientales el que vire a la complejidad explícitamente y solucione las tensiones que genera el dualismo en las ciencias ambientales o siga apuntando a la complejidad parcial y tácitamente mientras se permanece parcialmente en el dualismo. Aunque los estudios epistemológicos pueden colaborar en lo anterior, será principalmente la práctica de la investigación ambiental la que realmente apunte a lidiar con las tensiones de una forma o de otra.

\section{Agradecimientos}

Agradezco a la doctora María Eugenia Gonzalez Ávila por sus comentarios a un borrador de este texto. Agradezco también a la médico estomatóloga Jessica Herrera Montelongo por orientarme en la redacción de los párrafos que analizan la imagen de las células.

\section{Referencias}

Agudelo, Luis Carlos. (2005). Sobre la noción de territorio en la planificación. En Gestión y Ambiente, VII, 2: 39-48.

Aguilar Robledo, Miguel y Gabriela Torres Montero. (2005). Ambiente y cambio ambiental ¿Ejes para deconstruir y (re) construir la historia ambiental?. En Vetas. México: El Colegio de San Luis, VII (19): 8-33. 
Altschuler, Bárbara. (2013). Territorio y desarrollo: aportes de la geografía y otras disciplinas para repensarlos. Theomai. (27-28): 64-79.

Arnold, David. (2000). La naturaleza como problema histórico. El medio, la cultura y la expansión de Europa. México: Fondo de Cultura Económica.

Bachelard, Gastón. (1973). Epistemología Textos escogidos por Dominique Lecourt. Barcelona: Anagrama.

Bajtin, Mijail. (1987). Introducción. Planteamiento del Problema. La cultura popular en la Edad Media y el Renacimiento, 7-57. Madrid. Alianza Editorial.

Barrera de la Torre, Gerónimo. (2011) Berque, A. 2009, El pensamiento paisajero. En Investigaciones Geográficas, 75: 122-124.

Bateson, Gregory. (2006). Espíritu y naturaleza. Buenos Aires: Amorrortu.

Bertalanffy, Ludwig von. (1981). Historia y situación de la teoría general de sistemas. En Tendencias en la teoría general de sistemas, seleccionado y prologado por George J. Klir, 29-53. Madrid: Alianza Editorial.

Berque Agustin. (1997). En el origen del paisaje. En Revista de Occidente, 189: 7-21.

Bocco, Gerardo y Pedro Sergio Urquijo. (2013). Geografía ambiental: reflexiones teóricas y práctica institucional. En Región y Sociedad, 56(25): 75-101.

Bourdieu, Pierre. (2003). Los usos sociales de la ciencia. Por una sociología clínica del campo científico. Buenos Aires: Nueva Visión.

Brown, Harold L. (1998). La nueva filosofía de la ciencia. Madrid: Tecnos.

Camus Gayan, Pablo. (2001). Perspectivas de la "historia ambiental": orígenes, definiciones y problemáticas. Pensamiento Crítico Revista Electrónica de Historia, (1): 1-30.

Cano Suñén, Nuria. (2012). Definiendo el paisaje en base a la tensión. En Zainak Cuadernos de Antropología-Etnografía, 35: 117-138.

Cariño Olvera, Micheline. (2003). Aplicación de los postulados del manifiesto Historia a Debate a la investigación de la Historia Ambiental. Clío. 2(30): 39-49. 
Cariño Olvera, Micheline, Lorella Castorena y Antonio Ortega. (2013). Introducción: Conocimiento, valoración y problemática del oasis de los comondú. En Evocando el Edén. Conocimiento, valoración y problemática del oasis de los comondú, editado por Micheline Cariño, Aurora Breceda, Antonio Ortega y Lorella Castorena, 23-31. Barcelona, Icaria, 2013.

Carvalho, Ely Bergo de. (2010). História ambiental e o ensino de história: uma difícil aproximação. En Escrita de história, organizado por José Edson de Arruda Fanaia, Osvaldo Mariotto Cerezer y Renilson Rosa Ribeiro, 1-11. Cavalhada: UNEMAT, http://www.unemat.br/reitoria/editora/downloads/eletronico/escrita_da_historia.pdf $\quad(22$ de diciembre del 2014).

Cerezer y Renilson Rosa Ribeiro. (2002). História ambiental: muitas dúvidas, poucas certezas e um desafio epistemológico. Semana de Iniciação Científica. 2. Facultade Estadual de Ciências e Letras de Campo Mourão: 165-181.

Castro Herrera, Guillermo. (2013). Testimonios sobre el trabajo en historia ambiental. Sociedad Latinoamericana $\quad$ y http://solcha.uniandes.edu.co/index/index.php/testimonios (3 de febrero del 2016).

Castro Herrera, Guillermo. (2000). La crisis ambiental y las tareas de la historia en América Latina, en Papeles de Población. 37-60. http://redalyc.uaemex.mx/redalyc/src/inicio/ArtPdfRed.jsp?iCve=11202403\#at (25 de junio del 2010).

Castro Herrera, Guillermo. (2015a). Natura desde Marx. La pupila insomne. 15 de mayo. https://lapupilainsomne.wordpress.com/2015/05/15/natura-desde-marx/ (18 de agosto del 2015).

Castro Herrera, Guillermo. (2015b). Veritas filia temporis. Del ambiente como categoría política. Firmas Selectas. $\quad$ http://firmas.prensa-latina.cu/index.php?opcion=ver$\underline{\text { article } \& \text { author } I D=121 \& \text { articleID }=41 \& \mathrm{SEO}=\text { castro-herrera-guillermo-nils-veritas-filia-temporis- }}$ del-optimo-ambiental-como-categoria-politica (11 de agosto del 2015).

Claval, P. (1998). The Development of Regional Studies. En An Introduction to Regional Geography, 9-27. London: Blackwell Publishers. 
Cocho Gil, Germinal. (1999). Sobre la contribución de Prigogine, Haken, Atlan y el Instituto Santa Fe al estudio de la dinámica de los sistemas complejos. En Perspectivas en las teorías de sistemas, editado por Santiago Ramírez, 45-50. México: siglo xxi, UNAM.

Collado, Jaime. (2005). Servicios ambientales y servicios mercantiles relacionados con el ambiente, México, El Colegio de México / Universidad Nacional Autónoma de México / Fundación Gonzalo Río Arronte I. A. P., 2005.

Collingwood, Robin George. (2006). Idea de la naturaleza. México: Fondo de Cultura Económica.

Cronon, William. (1990). Modes of Prophecy and Production: Placing Nature in History. The Journal of American History. 4(76): 1122-1131.

Datri, Edgardo y Myriam Ortíz. (2004). Anexo III. El contexto pedagógico de la ciencia. En Introducción a la problemática epistemológica. Una perspectiva didáctica de las tensiones en la Filosofía de la Ciencia, editado por Edgardo Datri y Gustavo Córdoba. Rosario: Homo Sapiens.

Dieguéz Lucena, Antonio. (2005). La tesis de la inconmensurabilidad de las teorías. En Filosofía de la ciencia. 189-209. Madrid: Biblioteca Nueva, Universidad de Málaga.

Einstein, Albert. (2002). Sobre la teoría de la relatividad especial y general/Mis ideas y opiniones. Barcelona: RBA Coleccionables S. A.

Faucher, D. (2002). De los 'países' a las regiones. En El pensamiento geográfico, compilado por Josefina Gómez Mendoza, Julio Muñoz Jiménez y Nicolás Ortega Cantero, 280-288. Madrid: Alianza Editorial, S. A.

Feyerabend, Paul Karl (1989). Límites de la ciencia Explicación, reducción y empirismo. Barcelona: Paidós.

Figueroa Hernández, J. Adrián. (2003). Naturaleza, ecología, ambiente. La espiral del conocimiento y su retorno. San Luis Potosí: Ecoparadigma

Fleck, Ludwik. (1986). La génesis y el desarrollo de un hecho científico. Madrid: Alianza.

Foerster, Heinz von. (1991). Las semillas de la cibernética. Obras escogidas, editado por Marcelo Pakman y presentado por Carlos Sluzki. Barcelona: Gedisa, 1991. 
Foladori, Guillermo. (2005). Una tipología del pensamiento ambientalista. En ¿Sustentabilidad? Desacuerdos sobre el desarrollo sustentable, editado por Guillermo Foladori y N. Pierri, 83-136. México: Miguel Ángel Porrúa. http://www.universidad.edu.uy/retema/files/2013/10/Foladori.pdf (5 de agosto del 2015).

Gallini, Stefania. (2002). Invitación a la historia ambiental. Cuadernos digitales: publicación electrónica en historia, archivística y estudios sociales, 6, (18): 1-22.

Gallini, Stefania. (2004). Problemas de métodos en la historia ambiental de América Latina Penúltima versión entregada para publicación en el Anuario IHES, no. 19, 2004, pp. 147-171: 122.

https://www.academia.edu/210671/Problemas_de_m\%C3\%A9todos_en_la_historia_ambiental_1 atinoamericana (30 de marzo del 2015).

Galochet, Marc (2009). El medio ambiente en el pensamiento geográfico francés: fundamentos epistemológicos y posiciones científicas. En Cuadernos Geográficos, 44: 7-28. www.ugr.es/ cuadgeo/docs/articulos/044/044-001.pd (18 de abril del 2016).

García, Rolando. (2013). Sistemas complejos. Conceptos, método y fundamentación epistemológica de la investigación interdisciplinaria. México: gedisa.

Glacken, Clarence J. (2006). Ideas cambiantes sobre el mundo natural. Traducción de Guillermo Castro Herrera. Panamá, enero - julio 2006, pp. 1-22.

Glacken, Clarence J. (1997). Traces on the Rodhian Shore. Nature and Culture in Western Thought from Ancient Times to the End of the Eighteenth Century. Los Angeles: California University Press.

González de Molina, Manuel y Víctor M. Toledo. (2011). La historia ambiental y el fin de la utopía metafísica de la modernidad. Metabolismos, naturaleza e historia. Hacia una teoría de las transformaciones socioecológicas, 19-57 Barcelona: Icaria.

Grove, Richard H. (2001). Historia mediambiental. En Formas de hacer historia, editado por Peter Burke, 301-323. Madrid, Alianza Editorial.

Guzmán Ramírez, Gezabel y Martha Bolio Márquez. (2010). Poniendo en juego la herramienta perspectiva de género: algunas implicaciones psicosociales. Construyendo la herramienta perspectiva de género: cómo portar lentes nuevos, 43-63. México: Universidad Iberoamericana. 
Hacking, Ian. (1996). Representar e intervenir. México: Paidós/UNAM.

Hernández Briseño, Miguel Ángel. (2010). ¿Es el concepto de auto-organización un punto de convergencia entre filosofía y ciencia?. En Complejidad y pensamiento emergente, coordinado por Rodolfo Cortés del Moral y Javier Corona Fernández, 77-100. Guanajuato: Universidad de Guanajuato.

Hernández del Águila, Rafael y Francisco Toro Sánchez. (2012). Gestión sostenible de los recursos naturales y socioambientales. Gestión sostenible del ambiente: principios, contexto y métodos, editado por Francisco Serrano Bernardo y Luigi Bruzzi, 77- 103. Granada: Universidad de Granada.

Hobsbawm, Eric. (1998). Todos los pueblos tienen historia. En Sobre la historia, 176-182. Barcelona: Grijalbo.

Hughes, J. Donald. (2008). Three Dimensions of Environmental History. Environment and History. (14): 319-330.

Kahn, James R. (2005). Introduction. En The economic approach to environmental \& natural resources, 3-13. Ohio: Thompson.

Klimovsky, Gregorio. (1997). Las desventuras del conocimiento científico. Una Introducción a la epistemología. Buenos Aires: A-Z Editores.

Kuhn, Thomas S. (2006). La estructura de las revoluciones científicas. México: FCE.

Kuhn, Thomas S. (1993). La tensión esencial. Estudios selectos sobre la tradición y el cambio en el ámbito de la ciencia. Madrid: Fondo de Cultura Económica.

Leff, Enrique. (2006). aventuras de la epistemología ambiental: de la articulación de ciencias al diálogo de saberes, México: Siglo XXI.

Leff, Enrique. (2005). Construindo a História Ambiental da América Latina, Esboços, Florianópolis, (13): 11-30. http://www.periodicos.ufsc.br/index.php/esbocos/article/view/383/9913 (25 de diciembre del 2014). 
Leff, Enrique. (2002). saber ambiental. Sustentabilidad, racionalidad, complejidad, poder, México, PNUMA/Centro de Investigaciones Interdisciplinarias en Ciencias y Humanidades/siglo XXI, 2002.

Ley General del Equilibrio Ecológico y Protección al Ambiente reformada el 16 de enero del 2014 en http://www.diputados.gob.mx/LeyesBiblio/pdf/148.pdf (2 de diciembre de 2014).

Lezama, José Luis. (2001). El medio ambiente hoy. Temas cruciales del debate contemporáneo. México: El Colegio de México.

Lezama, José Luis. (2004). La construcción social y política del medio ambiente. México: El Colegio de México.

Lugo Hubp, José e Moshe Inbar. (2002). Desastres naturales en América Latina. En Desastres naturales en América Latina, compilado por José Lugo Hubp y Moshe Inbar, 9-33. México: FCE.

Macías García, Luis Fernando. (2010). Complejidad: dispositivo para pensar el movimiento de lo real en Sociología; una conjetura. En Complejidad y pensamiento emergente, coordinado por Rodolfo Cortés del Moral y Javier Corona Fernández, 61-76. Guanajuato: Universidad de Guanajuato.

Maldonado, Carlos Eduardo. (2009). Complejidad de los sistemas sociales: un reto para las ciencias sociales. Cinta de Moebio. (36): 146-157.

Marín, Juan Carlos. (s/f). Conversaciones sobre el poder (Una experiencia colectiva). Volumen 1. Buenos Aires: Ciclo Básico Común, Instituto "Gino Germani”.

Martínez Miguelez, Miguel. (1993). El paradigma emergente. Hacia una nueva teoría de la racionalidad científica. Barcelona: Gedisa.

Maturana, Humberto y Francisco Varela. (1999). El árbol del conocimiento. Las bases biológicas del conocimiento humano. Barcelona: Debate pensamiento.

Merchant, Carolyn. (1989). The Death of Nature. Women, Ecology and the Scientific Revolution, New York: HarperCollins. 
Miramontes Vidal, Octavio. (1999). Los sistemas complejos como instrumentos de conocimiento y transformación del mundo. En Perspectivas en las teorías de sistemas, editado por Santiago Ramírez, 83-92. México: siglo xxi, UNAM.

Montané, Julio. (1980). Marxismo y Arqueología, México, Ediciones Cultura Popular, 1980.

Morales Jasso, Gerardo. (2016) La apropiación de la naturaleza como recurso. Una mirada reflexiva. Gestión y Ambiente, (19): 141-154.

Morales Jasso, Gerardo y Jessica Herrera Montelongo. (2015-2016). Epistemología de la historia ambiental a través de una encuesta realizada en el VII Simposio de la Sociedad Latinoamericana y Caribeña de Historia Ambiental (2014). En HALAC Revista de la Sociedad Latinoamericana y Caribeña de Historia Ambiental, 1(5): 74-90.

http://revistas.unicentro.br/index.php/halac/article/view/3938 (19 de abril del 2016).

Morin, Edgar. (2007). Introducción al pensamiento complejo. Barcelona: gedisa.

O’Gorman, Edmundo. (2002). El arte o de la monstruosidad y otros escritos. México: Planeta, CONACULTA.

Ortiz Espejel, Benjamín, Guy Duval Berhmann, Bodil Andrade Frich, Marco Antonio Espinoza Guzmán y Sergio Madrigal González. (2011). Sistemas complejos e investigación participativa. Consideraciones teóricas, metodológicas y epistémicas para el estudio de las Organizaciones Sociales hacia la Sustentabilidad. Sociedades Rurales, Producción y Medio Ambiente. 11 (22): 133-150.

http://bidi.xoc.uam.mx/busqueda.php?indice=AUTOR\&tipo_material=TODOS\&terminos=Guy \%20Duval\%20Berhmann\&indice resultados=0\&pagina=1 (10 de junio del 2015).

Padilla Calderón, Esther. (2012a). Agua, poder y escasez. La construcción social de un territorio en un ejido sonorense, 1938-1955. Hermosillo: El Colegio de Sonora.

Padilla Calderón, Esther. (2012b) La construcción social de la escasez de agua. Una perspectiva teórica anclada en la construcción territorial. Región y Sociedad. 24(3).

Padua, José Augusto. (2010). As bases teóricas da história ambiental. En Estudos Avançados. 24(68): 81-101, http://www.scielo.br/pdf/ea/v24n68/09.pdf (20 de julio del 2015).

Pakman, Marcelo. (1991). Introducción. En Las semillas de la cibernética Obras escogidas de 
Heinz von Foerster, editado por Marcelo Pakman y presentado por Carlos Sluzki, 15-30. Barcelona: Gedisa.

Pérez Tamayo, Ruy. (1998). ¿Existe el método científico? Historia y realidad. México: El Colegio nacional, Fondo de Cultura Económica.

Real Academia Española. (2014). Diccionario de la Lengua Española Edición del tricentenario. $\underline{\text { http://dle.rae.es/?id=2HmTzTK y http://dle.rae.es/?id=OlWJe2D }}$ (2 de febrero del 2016).

Rodríguez, Rosa Elba. (2013). Comondú en el imaginario y la cultura indígena. En Evocando el Edén. Conocimiento, valoración y problemática del oasis de los comondú, editado por Micheline Cariño, Aurora Breceda, Antonio Ortega y Lorella Castorena, 163-201. Barcelona: Icaria.

Rojas Padilla, Johnny y Mario Alejandro Pérez-Rincón. (2013). Servicios ecosistémicos: ¿un enfoque promisorio para la conservación o un paso más hacia la mercantilización de la naturaleza?. En Sociedad y servicios ecosistémicos perspectivas desde la minería, los megaproyectos y la educación ambiental, editado por Mario Alejandro Pérez R., Johnny Rojas Padilla y Rodrigo Galvis, 29-59. Cali: Editorial Universidad del Valle.

Serna, Justo y Anaclet Pons. (2005). La Historia cultural: autores, obras, lugares. Madrid: Akal.

Serrano Bernardo, Francisco, Luigi Bruzzi y Enrique Toscano. (2012). Introducción al estado del ambiente. En Gestión sostenible del ambiente: principios, contexto y métodos, editado por Francisco Serrano Bernardo y Luigi Bruzzi, 21-44. Granada: Universidad de Granada.

Snow, Charles Percy. (1959). The two Cultures and the Scientific Revolution. New York: Cambridge University Press.

Soffiati, Arthur. (2013a). Como concebo a história ambiental. Rede Brasileira de História Ambiental 24 de febrero. http://www.historiaambiental.org/como-concebo-a-historiaambientalpor-arthur-soffiati/ (19 de agosto del 2015).

Soffiati, Arthur. (2013b). Fundamentos de eco-historia. Rede Brasileira de História Ambiental, 10 de mayo. http://www.historiaambiental.org/fundamentos-de-eco-historia-por-arthursoffiati/ (19 de agosto del 2015).

Stewart, Mart A. (1998). Environmental history: profile of a developing field. The History Teacher, 3 (31): 351-368. 
Swyngedouw, Erik, María Kaïka y Esteban Castro. (2002). Urban Water: A political-ecology perspective. Built Environment. 28, (2): 124-137.

Tellenbach, Hubertus y Bin Kimura (1989). The Japanese Concept of 'Nature'. En Nature As a Tradition of Thought. Essays in Environmental Philosophy. Editado por J. Beird Callicot y Roger T. Ames, 153-162. Albany: Sunny press.

Rodríguez, Rosa Elba. (2013). Comondú en el imaginario y la cultura indígena. En Evocando el Edén. Conocimiento, valoración y problemática del oasis de los comondú, editado por Micheline Cariño, Aurora Breceda, Antonio Ortega y Lorella Castorena, 163-201. Barcelona: Icaria.

Toledo, Víctor Manuel. (2016). La revolución de las hormigas. En La Jornada, 5 de enero, en http://www.jornada.unam.mx/2016/01/05/opinion/015a2pol (22 de febrero del 2016).

Toscano, Enrique y Luigi Bruzzi. (2012). Terminología y glosario en material de ambiente y sostenibilidad. En Gestión sostenible del ambiente: principios, contexto y métodos, editado por Francisco Serrano Bernardo y Luigi Bruzzi, 479-494. Granada: Universidad de Granada.

Valdivielso, Joaquín. (2008). Ecología y filosofía política. Ciudada y ciudadanía. Senderos contemporáneos de la filosofía política, editado por Fernando Quesada, 301-321. Madrid: Trotta.

Trinca Fighera, Delfina. (2006). Paisaje natural, paisaje humanizado o simplemente paisaje. En $\begin{array}{lllll}\text { Revistsa } & \text { Geográfica } & \text { Venezolana. } & 1 & \text { (47): }\end{array}$ http://www.redalyc.org/articulo.oa?id=347730363007 (17 de abril del 2016).

Urquijo Torres, Pedro Sergio y Narciso Barrera Bassols. (2009). Historia y paisaje. Explotrando un concepto geográfico monista. En Andamios. Revista de Investigación Social, 10 (5): 227-252, http://www.redalyc.org/articulo.oa?id=62811391009 (16 de abril del 2016).

Vargas Ulate, Gilbert. (2002). La geografía y el análisis del medio natural. En Reflexiones Revista de la Facultad de Ciencias Sociales de la Universidad de Costa Rica. 1 (80), http://revistas.ucr.ac.cr/index.php/reflexiones/article/view/11264 (17 de abril del 2016).

Wagensberg, Jorge. (1998). Ideas sobre la complejidad del mundo. Barcelona: Tusquets.

Wallerstein, Immanuel y la Comisión Gulbenkian. (2004). Abrir las ciencias sociales. México: siglo XXI. 
Worster, Donald. (1998). Appendix: Doing Environmental History. En The Ends of the Earth: Perspective in modern Environmental History, editado por Donald Worster, 297-307. Cambridge: Cambridge University Press.

Worster, Donald. (2000a). La historia como historia natural: un ensayo sobre teoría y método. En Las transformaciones de la tierra. Una antología mínima de Donald Worster, selección, traducción y presentación de Guillermo Castro Herrera, 13-26. Panamá. http://www.idea.unal.edu.co/proyectos/histamb1/Worsterespanol.pdf (5 de octubre del 2014).

Worster, Donald. (2000b). Transformaciones de la Tierra: hacia una perspectiva agro ecológica en la Historia. En Las transformaciones de la tierra. Una antología mínima de Donald Worster, selección, traducción y presentación de Guillermo Castro Herrera, 43-60. Panamá. http://www.idea.unal.edu.co/proyectos/histamb1/Worsterespanol.pdf (5 de octubre del 2014). 